\title{
Os Motivos da Escolha do Fogo nas Tentativas de Suicídio Realizadas por Mulheres
}

\author{
Karine Viana Maciel \\ Programa de Pós-Graduação em Psicologia da Universidade do Vale do Rio dos Sinos, \\ São Leopoldo, Rio Grande do Sul, Brasil \\ Elisa Kern de Castro ${ }^{1}$ \\ Centro de Ciências da Saúde da Universidade do Vale do Rio dos Sinos, São Leopoldo, \\ Rio Grande do Sul, Brasil \\ Priscila Lawrenz \\ Curso de Psicologia da Universidade do Vale do Rio dos Sinos, São Leopoldo, \\ Rio Grande do Sul, Brasil
}

\section{Resumo}

O objetivo do estudo foi compreender os significados da escolha do fogo como um dispositivo para a tentativa de suicídio em mulheres. Participaram oito mulheres que haviam sofrido queimaduras autoinfligidas e que estavam em acompanhamento médico ambulatorial para reparação das cicatrizes da queimadura em um hospital. Todas as participantes responderam a uma entrevista semiestruturada que investigava as suas histórias de vida, o momento de atear-se fogo e as motivações para tal ato, e a um questionário de dados sociodemográficos e clínicos. Constatou-se que o ato de atear-se fogo foi premeditado em alguns casos, mas não em outros. Para aquelas mulheres que premeditaram o ato, a escolha do fogo se deu porque esse seria um método eficaz para a morte. Para aquelas que atearam fogo sem premeditação, o uso do fogo parece ter sido impulsivo num momento de conflito e raiva, para chamar a atenção de alguém próximo, especialmente o companheiro e filhos. As mulheres não tinham conhecimento sobre as cicatrizes deixadas pela queimadura e do tratamento de recuperação que se seguiria.

Palavras-chave: Suicídio, tentativa de suicídio, queimaduras autoinfligidas, autoimolação.

\section{The Reasons to Choice of the Fire in Suicide Attempts Performed by Women}

\begin{abstract}
The purpose of this study was to understand the meaning of choosing fire as an option for attempted suicide among women. Participants were eight women who suffered self-inflicted burns and went under care for outpatient repair of burn scars at an hospital. Participants answered a semi-structured interview about the stories of their life, the moment and motivations to commit that act and a sociodemographic
\end{abstract}

1 Endereço para correspondência: Centro de Ciências da Saúde, Universidade do Vale do Rio dos Sinos, Avenida Unisinos, 950, Sala 2B 112, Bairro Cristo Rei, São Leopoldo, RS, Brasil 93022-000. E-mail: elisa. kerndecastro@gmail.com e karine.psico@yahoo.com.br

Agência de Financiamento: Universidade do Vale do Rio dos Sinos, bolsa pró-mestre.

Agradecimentos: as autoras agradecem à Universidade do Vale do Rio dos Sinos pela concessão do auxílio financeiro 'Pró-mestre' para a realização do mestrado da primeira autora.

O presente trabalho é parte da dissertação de mestrado da primeira autora, sob orientação da segunda autora, apresentado no Programa de Pós-Graduação em Psicologia da Universidade do Vale do Rio dos Sinos. 
and clinical data questionnaire. Results showed that the choice of fire was sometimes premeditated, but not always. For those women who premeditated the act, fire was chosen because it would be an effective method of suicide. For those who set fire without premeditation, the use of fire seems to have been an impulsive moment of conflict and anger, a way to call the attention of someone close, especially the partner and children. They had no knowledge of burn scars and subsequent treatment and recovery.

Keywords: Suicide, attempted suicide, self-inflicted Burns, self-immolation.

\section{Los Motivos de la Elección del Fuego en Intentos de Suicidio Realizados por Mujeres}

\section{Resumen}

El objetivo del estudio fue comprender el significado de la elección de fuego como un dispositivo para el intento de suicidio en mujeres. Participaron ocho mujeres que habían sufrido quemaduras autoinfligidas y estaban bajo el cuidado de reparación de las cicatrices en un hospital. Todas las participantes contestaron a una entrevista semi-estructurada para investigar sus historias de vida, el momento de incendiarse a sí mismas y las motivaciones para el acto y un cuestionario de datos sociodemográficos y clínicos. Los hallazgos mostraron que el acto de incendiarse fue premeditado para algunas mujeres, pero no para todas. Para aquellas mujeres que premeditaron el acto, la elección del fuego sería un método eficaz para la muerte. Para las que se incendiaron sin premeditación, el uso del fuego fue un momento impulsivo de conflictos e ira para llamar la atención de alguien cercano, especialmente la pareja y sus hijos. Las mujeres no tenían conocimiento sobre las cicatrices de quemaduras, de la recuperación y tratamiento que seguirían.

Palabras clave: Suicidio, intento de suicidio, quemaduras autoinfligidas, inmolación.

O significado do termo suicídio tem origem no latim, em que sui refere-se a si mesmo, e $c a$ ederes diz respeito à ação de matar, explicitando a morte intencional ou autoinfligida. O suicídio geralmente inicia com pensamentos autodestrutivos, seguindo para as ameaças até chegar ao ato da tentativa de suicídio ou sua própria consumação (Werlang \& Botega, 2004). A interação entre fatores psicológicos, sociais, biológicos, culturais e ambientais tem importante influência na tomada de decisão de cometer o suicídio (Werlang, 2012).

São muitas as formas escolhidas para a tentativa de suicídio, e as queimaduras autoinfligidas pode ser uma delas, utilizando-se, para isso, o fogo e seus aceleradores. Essa é considerada uma das formas mais dramáticas e fatais dentre todas, estando relacionado a questões culturais e políticas, principalmente nos países do Ocidente (J. L. S. Macedo, Rosa, \& Silva, 2011). A queimadura produz cicatrizes desfigurantes e a sua recuperação é dolorosa física e psiquicamente (Rezaie, Khazaie, Soleimani, \& Schwe- bel, 2011). Situações desse tipo acontecem com maior incidência nas sociedades em desenvolvimento do que em países desenvolvidos (Ahmadi et al., 2009).

Estudos têm mostrado que a grande maioria dos sujeitos que cometem tentativa de suicídio através do fogo é do sexo feminino (Ahmadi et al., 2009; Hanna \& Ahmad, 2009; Mabrouk, Omar, Massoud, Sherif, \& Sayed, 1999; Macente, Santos, \& Zandonade, 2009; Rezaie et al., 2011; Taghaddosinejad, Sheikhazadi, Behnoush, Reshadati, \& Anary, 2010). Dentre os motivos mais frequentes nesses casos estão os problemas afetivos e as dificuldades financeiras, podendo haver, inclusive, uma associação entre ambos (Ahmadi et al., 2009; Makhlouf, Alvarez, $\&$ de la Grandmaison, 2011).

A autoimolação pode ser praticada como parte de costumes étnicos, chegando a até $50 \%$ dos casos das tentativas de suicídio que se realizaram com sucesso em países do Oriente (Ahmadi, Mohammadi, Stavrinos, Almasi, \& Schwebel, 2008). Situações como essa podem 
chegar a $9 \%$ das causas de internações por queimaduras nos países do Ocidente (Ahmadi \& Ytterstad, 2007). Apesar de ser incomum nessa região, trata-se de uma experiência dramática com sequelas gravíssimas, de ordem psíquica, estética e funcional (O’Donoghue et al., 1998).

Os estudos existentes sobre tentativa de suicídio pelo uso do fogo são, em geral, baseados em prontuários (Ahmadi \& Ytterstad, 2007; Chan \& Burd, 2012; Daigeler et al., 2009). Nenhum estudo foi encontrado até o momento em que se tenha explorado os motivos pela escolha do fogo em sobreviventes de tentativas de suicídio. No Brasil, apesar de existirem pesquisas sobre suicídio, essa temática específica também é ainda desconhecida. Assim, o presente estudo teve como objetivo compreender os significados da escolha do fogo como um dispositivo para a tentativa de suicídio em mulheres.

\section{Método}

\section{Delineamento}

Trata-se de uma pesquisa qualitativa de natureza exploratória (Flick, 2002/2004; Gil, 2010).

\section{Participantes}

Participaram mulheres que tentaram suicídio através do uso do fogo há pelo menos um ano e meio, tempo suficiente para que, nesse período, as feridas já estivessem em processo de cicatrização e elas já tivessem experenciado algum tipo de contato com o meio social. Foram convidadas a participar do estudo doze pacientes escolhidas por conveniência entre aquelas que realizavam tratamento para reparação das sequelas de queimaduras em um hospital referência em atendimentos de emergência. Desses pacientes, oito aceitaram participar da pesquisa. Com relação às demais, duas marcaram por mais de uma vez um horário para a realização da entrevista e não compareceram; uma não conseguiu compatibilizar horário para realização da entrevista porque morava em outra cidade; e a última iniciou a entrevista, mas durante o seu percurso admitiu que foi o seu parceiro e não ela quem ateou fogo no seu corpo, sendo a mesma excluída da pesquisa.
Todas as participantes eram adultas, com idades que variaram entre 24 e 55 anos, quatro delas jovens adultas e as outras quatro mulheres maduras. $\mathrm{O}$ tempo médio em que elas sofreram a queimadura foi de 3,75 anos $(D P=2,76)$. A Tabela 1 mostra as principais características sociodemográficas e clínicas das participantes:

\section{Instrumentos}

Questionário de Dados Sociodemográficos e Clínicos. Continha informações sobre idade da paciente, escolaridade, estado civil, filhos, renda familiar, etc., além de dados sobre sua saúde atual.

Entrevista Semiestruturada sobre a Tentativa de Suicídio. Investigou a história de vida das participantes, o momento de atear-se fogo, a experiência da queimadura, seu atual contexto de vida, os sentimentos após o ato, a reinserção social e como a queimadura tem afetado no seu dia a dia e sua saúde psíquica e física. Para o presente trabalho, serão apresentados apenas os resultados referentes ao ato de atear-se fogo.

\section{Procedimentos Éticos e de Coleta dos Dados}

Primeiramente, realizou-se um contato com a psicóloga responsável pelo atendimento na Unidade de Queimaduras e com o coordenador deste setor no hospital, a fim de se verificar a possibilidade de realização da pesquisa. Após a apresentação do projeto, o mesmo foi aprovado pelos Comitês de Ética da Universidade do Vale do Rio dos Sinos e do Hospital Cristo Redentor de Porto Alegre.

A coleta de dados foi realizada entre os meses de junho e setembro de 2012, em uma sala de ambulatório do hospital. A abordagem às pacientes na instituição foi realizada a partir da indicação da psicóloga do local, que remetia para a pesquisa aquelas pacientes que estavam ou estiveram sob seu atendimento e que haviam tentado suicídio através do fogo. O convite para participar da pesquisa com as pacientes foi realizado por telefone ou nos dias de consulta médica das pacientes, ocasião em que era agendada a realização da entrevista. As entrevistas foram gravadas e posteriormente transcritas na íntegra. 


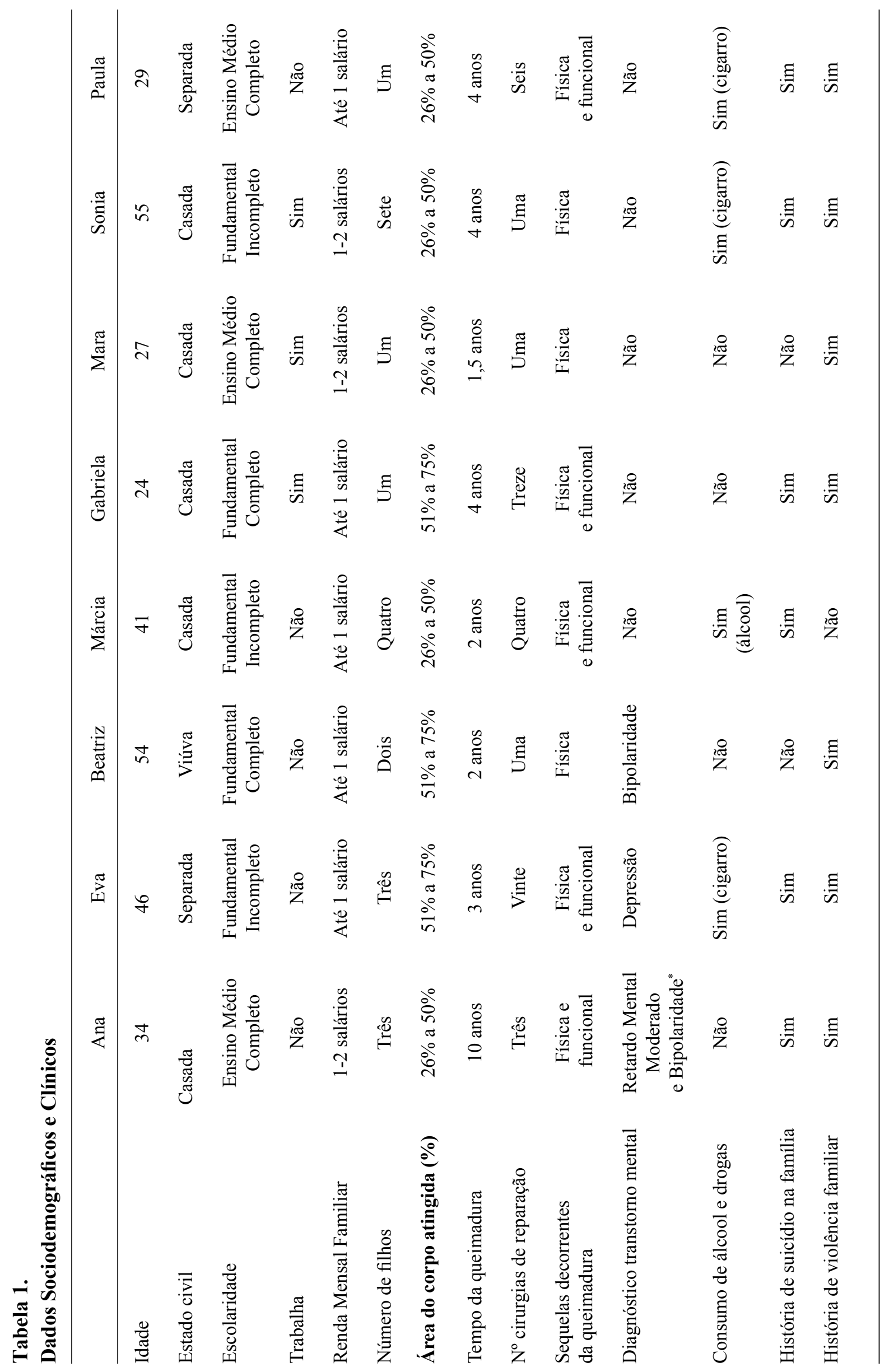




\section{Análise dos Dados}

As entrevistas foram submetidas à análise de conteúdo, que processa os dados através de procedimentos analíticos, até a transformação destes em uma análise clara, criteriosa e original (Gibbs, 2009). Após a leitura flutuante do material, foram criadas as categorias e realizada a codificação das unidades de sentido. Para isso foi realizada a identificação e o registro de passagens do texto com a mesma ideia teórica e descritiva. Feito isso, identificou-se duas categorias, as quais estão subdivididas em subcategorias, a fim de se explorar e interpretar melhor a temática.

\section{Resultados e Discussão}

Na Tabela 2 são apresentadas as categorias e subcategorias, originadas a partir dos relatos das participantes:

\section{Tabela 2}

\section{Categorias e Subcategorias}

\begin{tabular}{|l|l|}
\hline Categorias & Subcategorias \\
\hline
\end{tabular}

1. Antecedentes ao ato de atear fogo em seu próprio corpo

2. O momento e os motivos de atear-se fogo
1.1 História de Violência

1.2 Fragilidade nas relações interpessoais

1.3 Dificuldades individuais

1.4 Sofrimento psíquico e distúrbios mentais

1.5 Tentativas de suicídio anteriores

$1.6 \mathrm{O}$ conflito desencadeador

2.1 Tentativa de suicídio confessa/declarada

2.2 Ato impulsivo para chamar a atenção de alguém e/ou apagar a sua própria dor

2.3 "Eu não faria, como aconteceu eu não sei!"

Nota. 'Os diagnósticos de transtornos mentais aqui expostos foram relatados pelas pacientes, que disseram ter sido diagnosticado por psiquiatras.

\section{Antecedentes ao Ato de Atear Fogo em seu Próprio Corpo}

Nessa categoria foram incluídas as falas que abordam as experiências de vida das participantes, anteriores ao ato da tentativa de suicídio com o fogo e que podem ter alguma relação com as queimaduras autoinfligidas. Ainda que essas mulheres tenham histórias de vida diferentes, alguns aspectos parecem ser comuns no que diz respeito ao tema em questão.

História de Violência. As falas das participantes apresentaram semelhanças no que se refere ao histórico de violência vivenciado na infância e/ou na idade adulta, com conteúdos de agressões sofridas por elas próprias ou de situações de violência que presenciaram. $\mathrm{O}$ agressor geralmente era um familiar, podendo ser o pai ou o marido e, em alguns casos, as participantes tiveram tal experiência com ambos. A violência dirigida a elas era física e verbal:
O meu pai batia muito na minha mãe. Quando eu tinha seis anos, eu bem dizer, salvei a minha mãe. O meu pai tava batendo na minha mãe e a minha mãe prensou a... o pescoço dela, entre a porta do roupeiro . . .e, eu era muito espancada pelo meu pai, meu pai me batia muito. Depois eu casei, dai eu era desprezada pelo meu marido, maltratada pelo eu marido. (Mara $\left.{ }^{2}\right)$

O histórico de abuso sexual também esteve presente no relato de algumas participantes. Esse abuso vinha tanto do marido, de outros membros da família ou de algum conhecido:

Isso foi quando a minha irmã namorou um senhor, ai eu já tinha uns 13 anos. E um dia ele me chamou e começou a passar as mãos nos meus seios. E, outra vez que aconteceu

2 Os nomes aqui apresentados são fictícios para preservar a identidade das participantes. 
isso, foi quando a minha irmã casou com um outro . . . e daí ele passou a mão nos meus seio e nas minhas perna ... (Ana)

Na época que a minha mãe era viva, uma amiga nossa, ela tinha um padrasto e o padrasto dela violentou ela. Só que ela não contou pra mãe dela e não contou pra gente. Daí eu também ia às vezes posar lá, ele fez... abusou e ameaçou que ia fazer e acontecer se nós contasse pra mãe! (Sonia)

A partir destes relatos pode-se pensar que possivelmente as participantes não se sentiram à vontade para relatar o que estava acontecendo a seus familiares ou porque achavam que sua família não as apoiaria e, ainda, ficaria contra elas, ou mesmo por ameaças realizadas pelo abusador. As situações de violência relatadas mostram que essas mulheres viviam em condições de vulnerabilidade psicológica que possivelmente contribuíram para o seu quadro de sofrimento, que culminou na tentativa de suicídio. A violência doméstica, em algumas situações, pode aparecer como um precedente da decisão da tentativa de suicídio pelo uso do fogo, em que a vítima entende o ato como uma solução que cessaria as agressões vividas. Os conflitos familiares podem aumentar até dez vezes os riscos desse acontecimento (Ahmadi et al., 2009).

Fragilidade nas Relações Interpessoais. As relações interpessoais das pacientes, segundo seus relatos, pareciam estar bastante fragilizadas. As pacientes relataram que saíram cedo de casa em função de dificuldades de relacionamento familiar:

Meu pai dizia que eu não tava trabalhando, que eu tava na rua fazendo ponto ... A gente brigou, ele me bateu, porque eu fui rebelde com ele, no outro dia eu botei minha malinha e fui embora de casa, com 15 anos. Sofri tanto a falta da família. A minha mãe nunca foi sequer ver aonde eu morava. (Eva)

Essas mulheres parecem não se sentir importantes no convívio com suas famílias. Observa-se que os conflitos acabavam por denunciar a desvalorização, a falta de confiança e de segurança, bem como situações de abandono vivenciadas por elas. Para Prieto e Tavares (2005), a existência de graves conflitos de relacionamento e perdas interpessoais são eventos preceptores significativos, podendo ser precipitadores ao ato do suicídio ou tentativa de suicídio.

Algumas participantes relataram também terem tido perdas significativas tanto na infância quanto na adolescência e, ao falarem disso, parecem ainda não ter elaborado essas perdas e permanecer vivendo tais conflitos:

A minha mãe, ela faleceu quando eu tinha seis anos e eu e meus irmãos, a gente ficou um pouco rolando no mundo. Quando ela faleceu, eles ligaram pro meu pai, pra ver se ele não queria ficar com a gente, que a gente era em três, e daí o que ele fez, ele não quis saber! (Gabriela)

A perda de um familiar, como relatado acima, tem impacto no modo como as pessoas organizam suas vidas. Alguns estudos (Ahmadi et al., 2008; Ahmadi \& Ytterstad, 2007) sugerem a existência de alguma relação entre a morte dos pais e a tentativa de suicídio com o uso do fogo. Possivelmente isso se justifica pelo significado que tem para essas participantes a perda de uma referência, especialmente quando isso ocorre precocemente. A partir daí, é possível pensar que, como elas tiveram dificuldades para lidar com essa perda, permanecem ao longo de suas vidas encontrando barreiras para lidar com outras que vão surgindo no decorrer do tempo.

No que se refere às relações sociais mais amplas, várias participantes relataram terem tido relações escassas de amizade e convívio social anteriores à queimadura: "Só tenho uma amiga..." (Beatriz); "Eu não tenho assim, convívio com ninguém, com vizinhos, eu sou muito calada, fico muito quieta. Fico só dentro de casa assistindo televisão. É só oi pra lá, oi pra cá! Não vou na casa de ninguém!" (Márcia). A fala das participantes corrobora com os achados de um estudo realizado por Gaspari e Botega (2002) que ao avaliarem a rede de apoio social de pacientes que tentaram suicídio encontraram que esses não se sentiam importantes para sua rede social, viviam em núcleos familiares disfuncionais e apresentavam dificuldades em ocuparem seus lugares perante a sociedade.

A falta ou a ausência de amigos, de pessoas em quem pudessem confiar pode ter contribuído 
para que seu sofrimento se agravasse a ponto de colocarem seus corpos em chamas. Portanto, fica subentendido que essas mulheres não tiveram alguém com quem se sentissem seguras para dividir suas angústias, dificuldades, insatisfações e problemas. Parece que seus relacionamentos com o outro se limitava a seus parceiros, atingindo no máximo a outros membros de sua própria família, com quem muitas vezes mantinham uma relação distante, conforme visto anteriormente, contribuindo para que as mesmas se sentissem sozinhas.

Dificuldades Individuais. Referem-se especialmente à dificuldade de falar e expressar seus sentimentos, o que pode estar relacionado diretamente ao atear-se fogo como uma forma de comunicação com outras pessoas. Essas mulheres acabavam muitas vezes se calando e guardando para si o que pensavam sobre determinadas situações:

. . quando eu era pequena, eu era um bicho do mato, porque eu nunca pude falar as coisas porque eu tinha medo . . . Eu era muito fechada, não falava nada ... Sempre fui quieta! (Ana)

Daí eu fiquei guardando muita coisa na cabeça, aquela irritação foi acumulando bastante coisa na cabeça . . às vezes, também eu me tranco, me fecho, fico muito calada e fico magoada e fico irritada e às vezes eu evito de falar. (Márcia)

Todas essas emoções reprimidas foram se acumulando e podem ter colaborado a levá-las à situação extrema de atear-se fogo. Essa dificuldade em expressar a agressão e a raiva acaba por prejudicá-las nos momentos de tentarem resolver seus problemas. Sendo assim, o ato de atear-se fogo pode ter representado em suas vidas uma forma de dar lugar a um excesso de angústia que não foi elaborado psiquicamente. Para M. M. K. Macedo e Werlang (2007), a pessoa acaba representando através de um ato aquilo que poderia ter sido expresso pela via da fala devido a uma falha na simbolização das vivências traumáticas que ocorreram ao longo da vida desses sujeitos.

Sofrimento Psíquico e Distúrbios Mentais. Dentre as participantes deste estudo, três delas já haviam sido diagnosticadas com algum transtorno mental por psiquiatra no passado, e duas destas tinham o diagnóstico de depressão. Ana relatou ter depressão e bipolaridade e referiu também que o psiquiatra deu um diagnóstico F71 (Retardo Mental Moderado). Eva tem depressão e faz acompanhamento eventual com a psicóloga no hospital onde trata as sequelas das queimaduras. Beatriz referiu ter sido diagnosticada pelo psiquiatra com transtorno bipolar, ainda que, segundo seu próprio relato, a psicóloga que a atende não concorde com tal diagnóstico.

A presença de transtornos mentais em pessoas que tentaram suicídio através do fogo já foi apontada por diversos autores (Ahmadi et al., 2008; Alaghehbandan, Lari, Joghataei, Islami, \& Montavalian, 2011; J. L. S. Macedo et al., 2011). A depressão parece ser o transtorno com maior incidência nos casos de tentativas de suicídio em geral (Santos, Lovisi, Legay, \& Abelha, 2009). Histórias de distúrbios psiquiátricos são também frequentemente identificadas nos sujeitos que tentam suicídio com o uso do fogo. Em uma unidade de internação de vítimas de queimaduras, dois terços de todas as vítimas de suicídio possuíam comorbidades preexistentes, e em média $30 \%$ dos pacientes, homens e mulheres, tinham distúrbios psiquiátricos como depressão, transtorno borderline e esquizofrenia (Forster et al., 2012). Em outro estudo, dois terços da amostra apresentaram distúrbios (Rothschild, Raatschen, \& Schneider, 2001).

Ainda que as outras participantes não tenham relatado diagnóstico de transtorno mental, alguns relatos denunciavam a existência de sofrimento psíquico intenso que afetavam suas vidas e declaravam suas limitações para lidar com algumas situações: "É, eu tinha muita ansiedade, assim né! É... mudanças de humor, tinha dias que eu tava irritada, dias que eu tava bem, né?! Não conseguia dormir de noite!" (Márcia); "Não precisava ter nada muito... [motivo para tentar se matar] assim... é imaginar que eu tivesse fazendo com os outros. Isso também é muito normal! É maltratar os outros, é querer que coisas ruins acontecessem!" (Paula). Assim, é possível afirmar que, além do sofrimento psíquico intenso, as demais pacientes também pu- 
dessem ter distúrbios psiquiátricos, porém não haviam sido diagnosticadas por psiquiatra.

Tentativas de Suicídio Anteriores. Algumas das participantes tinham história de tentativas de suicídios anteriores. Ana relatou ter realizado outras tentativas através do enforcamento e ingestão de medicamentos:

Eu nunca aceitei a morte da minha mãe. Quando eu caí em depressão, eu sempre quis morrer, só que nunca foi assim... negócio de fogo! E sempre foi em eu pegar uma corda, quando era... se elas [irmãs] me deixassem assim... solta; ou os remédios.

Paula relatou ter tentado o próprio suicídio desde criança, mas como um ato de curiosidade e comportamentos autodestrutivos:

Desde criança! Sempre por nada, só a vontade, curiosidade... sabe quando dá aquela vontadezinha, que fica te incomodando... de tentar suicídio.... eu já me joguei dentro dum lago, que tinha atrás de casa... eu tinha uns oito anos eu acho. . . . Aí a outra vez eu tentei me enforcar, não deu muito certo, escapou a mangueira. Aí eu tinha uns 12 anos. Aí, pra machucar de vez em quando, eu amarrava uma cinta no pescoço e ficava puxando, só pra sentir adormecer, os olhos pesavam assim... e eu dormia. Tomei veneno pra formiga, não me fez nada. Ai eu já tinha uns 17, 18 anos.

As histórias de tentativas de suicídio anteriores devem ser entendidas como um importante fator de risco a ser considerado (Chan \& Burd, 2012; Daigeler et al., 2009). No primeiro relato, a participante declara sua intenção de morrer por não tolerar a perda da mãe (adotiva) que fora uma figura significativa em sua vida, a mesma vê nos comportamentos suicidas uma saída para o seu sofrimento; já no segundo relato, a participante declara certo prazer nos atos que realiza, testando todos os limites possíveis desde a infância. Ela não atribui os acontecimentos relatados a algum fato específico, o que possivelmente é decorrente de sérios conflitos psíquicos não identificados na ocasião.

Márcia, Gabriela e Sonia referiram que realizaram outras tentativas de suicídio devido a problemas conjugais: "A gente brigava, e eu lembro que eu morava numa faixa e ficava ameaçando ele que eu ia me jogar. Dai tinha tipo um perauzinho, mas não era muito!' (Gabriela); "Uma vez, eu tomei uns comprimidos. Na época que ele andava me traindo" (Sonia). Esses relatos declaram o envolvimento de seus parceiros na realização desse ato. Para Ahmadi et al. (2009) experiências como esta comprovam a existência de significativos conflitos com os mesmos, anteriormente ao ato realizado com o fogo.

O Conflito Desencadeador. Todas as participantes relataram dificuldades vividas naquele momento em suas vidas e que de alguma forma estavam relacionados ao ato de por fogo em seus próprios corpos. A cena se apresenta na maioria das vezes em meio à emergência de um conflito conjugal. Apareceram conflitos que estavam relacionados a questões familiares:

Nós [ela e o atual marido] tinha brigado um monte! Foi, no meio de uma discussão, eu tava com muito problema na minha cabeça. O meu filho também se envolveu com drogas ... As incomodações com ele [marido] também em casa, bebia demais e me incomodava muito... bahh!!! (Márcia)

"Acho que eu juntei um pouco de tudo! De ele não ter nunca me dado atenção [referindo-se ao pai], também. E das brigas com o marido!" (Gabriela). Para Hanna e Ahmad (2009) grande parte dos sujeitos realiza o ato da tentativa de suicídio com o uso do fogo na esperança de solucionar problemas interpessoais crônicos ou com a finalidade de atingir seu parceiro ou algum familiar, fazendo-os se sentirem culpados pelo ocorrido.

A existência de ciúmes e insegurança nos relacionamentos e as dificuldades dessas mulheres em lidar com tais situações também foram mencionados nas entrevistas: "Ele [ex-marido] sempre foi muito ciumento, muito, sei lá! Com acusações que não devia" (Eva);

Ciúmes! Porque ele sabia do meu passado. Então ele sempre acabava me jogando isso . . Ele me conheceu numa boate e ele me tirou da boate . . como ele tinha ciúmes, como ele tem um certo sentimento de posse sobre mim, ele acreditava em certas coisas na cabeça dele e... sei lá! (Paula). 
Além disso, histórias de traição e o medo do descaso por parte de seus parceiros também se fizeram presentes em seus relatos:

Eu tinha muito medo que ele fosse embora, que eu ficasse sozinha, sabe?! Ah, eu morria, se ele dissesse que ia ir embora! Tanto é que a gente se separou duas vezes antes de acontecer tudo isso. E a gente acabou voltando. (Mara)

As histórias de ciúmes e traições estavam diretamente relacionadas às inseguranças, tanto por parte das participantes quanto de seus parceiros. As ideias de traição, a possibilidade de uma relação triangular e o ciúme excessivo intensificaram a insegurança em relação à possibilidade de separação e a angústia de abandono.

É possível que o ato de atear-se fogo tenha sido realizado com a finalidade de chamar a atenção de alguém que estava muito próximo como uma forma encontrada por elas de envolver o outro na cena traumática, mas também pode-se pensar que este ato possa ter ocorrido com o intuito de apagar a dor sentida por elas a partir dos conflitos que vivenciavam. As participantes Beatriz e Sonia realizaram o ato diante de suas filhas, apresentando um discurso prévio ao momento da cena que parecia ter a intenção de provocá-las: "E eu disse assim... 'Patricia [filha], tu quer ver o que eu faço, tu quer ver o que é que eu vou fazer?"' (Beatriz).

Eu não me lembro, mas... peguei a garrafa de álcool e cheguei no quarto da minha guria [filha] e disse pra minha guria . . . "Olha o que eu faço comigo"! E joguei o álcool em cima de mim e risquei o... eu sei que ele [esposo] avançou em mim, veio e me puxava, me puxando, até derramou por tudo. E na hora assim, eu vi meu gurizinho assim... chorando, né?! (Sonia)

Já, Eva, Gabriela e Mara realizaram o ato diante de seus parceiros, chocando-os: “. . . tava [em casa] ele [marido] e o Bruno [filho], que é o caçula. Ele tava deitado na minha cama e eu fiz na suite, no banheiro do quarto" (Eva);

Ele [marido] tinha saído e voltou tarde, dai eu comecei a brigar um monte com ele e dai eu não sei o que que ele falou comigo que eu disse pra ele: - "Ah, então tu vai ver o que que eu vou fazer!" Só que aquilo ele não deu muito ... e daí ele pegou e foi se deitar. Daí eu peguei sentei ali, peguei uma garrafa de álcool e me toquei. (Gabriela)

Já fazia uma semana que eu não dormia e tinha que ir trabalhar no outro dia. Daí, eu tentei conversar com ele, ele disse que não queria conversar comigo. Aí eu disse: - "vamos dormir!" E, ele disse: - "eu não vou dormir contigo!" Aí eu disse: - "ahh é, então tu não vai dormir comigo!! Então tá!!" Aí eu fui lá no quarto, peguei o vidro de álcool, peguei o isqueiro e taquei álcool nos cobertor que ele tava tapado no sofá. E daí eu apaguei e fui pra 'banda' da cozinha assim... ai eu disse: "ahh, tu não quer conversar comigo, então tá!!" E daí eu peguei, taquei álcool em mim e botei fogo. (Mara).

\section{O Momento e os Motivos de Atear-Se Fogo}

$\mathrm{O}$ que aconteceu no momento em que essas mulheres atearam fogo nos seus corpos e o que as levou a esse ato foi distinto para cada uma delas, podendo o mesmo ter sido um ato voluntário ou não.

Tentativa de Suicídio Confessa/Declarada. Algumas das participantes reconheceram a sua intenção e finalidade de alcançar a morte com o ato de por fogo em si mesma. Para elas, a única possibilidade de um 'depois' do ato era a morte, parecia para elas que a escolha do fogo permitiria que isso acontecesse:

Eu tive tempo naquele dia pra pensar, sabe?! Eu tive tempo, eu tive tempo pra raciocinar, pra não fazer, sabe?! Porque eu fui na casa do meu filho e peguei o álcool... o isqueiro não funcionou, eu tive tempo pra ir pegar outro isqueiro, sabe?! (Beatriz)

Com relação às sequelas e marcas deste ato, elas referiram:

Na hora eu só pensei... eu só queria morrer! Eu queria morrer mesmo, não tava nem ai se... no que que aquilo ali ia provocar, né?! Que eu ia viver e que eu ia ficar com aquilo ali depois! (Márcia)

A prioridade nestes casos estava em encontrar a morte, possivelmente por isso, as partici- 
pantes não pensaram nas marcas da queimadura, por não acreditarem que haveria um depois, entendiam que aquele ato seria fatal e solucionaria os conflitos que vivenciavam naquele momento, na medida em que acreditavam que suas vidas se finalizariam ali.

Conforme a intensidade do sofrimento causado por uma determinada situação, pode ocorrer a incapacidade do sujeito em dar um sentido à dor psíquica produzida a partir do acontecimento. Surge então, a ideia de dar fim à sua própria vida, sendo essa representada através de um ato (M. M. K. Macedo \& Werlang, 2007). A dificuldade em elaborar perdas diante de um desequilíbrio emocional e psicológico pode acabar incidindo em um comportamento de autodestruição (Ferreira \& Luis, 2002). Esses sujeitos acabam identificando no ato uma possibilidade de transformar em cinzas todas as questões difíceis que permeavam suas vidas e com as quais não conseguem lidar.

Ato Impulsivo para Chamar a Atenção de Alguém elou Apagar a sua Própria Dor. Houve relatos em que as participantes declararam não ter planejado previamente a realização do ato; não estava claro para elas a intenção que tinham com a cena que construíram. Ainda que afirmem não ter pensado em nada no momento do ato de atear fogo em seus corpos, aparece também nos relatos a ideia de que não existia a intenção de encontrar a morte de fato, mas possivelmente o intuito de amenizar a dor que as angustiava naquela situação: "Eu não digo que foi uma tentativa de suicídio. Porque eu não pensei em me matar. Eu quis... eu nem sei o que quis! Eu já me perguntei várias vezes ... eu nem pensei assim, simplesmente fiz!" (Eva); "Não pensei, simplesmente foi um ato impensado o que eu fiz" (Mara); “. . . eu tão inconsequente, fiz sem pensar" (Paula).

Evidências empíricas (Ahmadi, 2007; Ahmadi \& Ytterstad, 2007) mostram que as mulheres que cometeram com sucesso a autoimolação não tinham a intenção de cometer suicídio, podendo ser esse ato entendido como um parassuicídio. Além disso, algumas participantes reconhecem a intenção que tinham com esse ato de chamar a atenção de algum membro importante de suas famílias (esposo, pais), o que declara a voluntariedade do ato de atear-se fogo, mas não a intenção de morrer: "Eu quis dar um susto nele [esposo], mas eu não avaliei as consequências do que eu tava fazendo" (Eva); "Na minha cabeça, eu não queria me matar, era só uma forma de causar, de chamar atenção. Acho que tipo que nem criança, eu queria chamar a atenção, do meu marido, do meu pai, sei lá, das pessoas assim!!" (Gabriela). Esse comportamento pode também ser entendido como um parassuicídio, ou seja, essas mulheres tinham a intenção de chamar a atenção de alguém próximo, mas não tinham conhecimento sobre a gravidade das sequelas produzidas pelo fogo e não tinham o desejo de morrer.

Quando questionadas sobre o(s) motivo(s) da escolha do fogo, as participantes relataram não saber o motivo. Elas não entendiam esta como uma escolha e sim como uma opção de fácil acesso naquele momento de raiva: "Eu não sei... não sei te dizer! Eu não escolhi nada, era o que tava ali. Como eu fumo, casualmente o isqueiro tava ali. Não foi uma escolha!" (Eva). Ou seja, naquele momento em que se deixaram tomar pela impulsividade, acessaram ao instrumento que estava diante delas (no caso, o álcool) com o intuito de atingir ao outro, sem pensar nas conseqüências daquele ato (Ahmadi, 2007).

"Eu Não Faria! Como Aconteceu Eu Não Sei!". Houve relatos que declararam que a culpa pelo ocorrido seria de alguma força maior que tomou conta de seus corpos no momento do ato, atribuindo assim, $o$ ato a uma questão de ordem espiritual ou sem explicação, encobrindo a intencionalidade do ato:

Não, da minha parte não [refere-se a não ter planejado o ato]! . . . não foi uma coisa assim planejada ... Por que eu também fiquei me perguntando o por quê! E uma coisa assim que dizem, que eu tinha que ir numa casa espirita. Mas eu não acredito nisso! Ai as vezes eu me pergunto, será que era mesmo uma coisa, será que era eu? . . mas diz que quando isso aconteceu não era eu e não era a minha voz. Diziam que uma pessoa dizia assim: - "ah eu vou matar e vou levar ela embora!" (Ana) 
Quando dizem... "aí como é que tu pôde fazer isso?!" Eu digo: - "eu, eu não faria!" Como aconteceu, eu não sei. Eu não faria! E nem agora eu faria! . . E eu vou te dizer, eu jamais iria tentar me matar e nem penso em me matar! Eu não sei o que que aconteceu. (Sonia)

\section{Considerações Finais}

O presente estudo buscou compreender as experiências vivenciadas por mulheres que atearam fogo em seus corpos, como uma possibilidade de saída para os conflitos que permeavam suas vidas. Verificou-se que independentemente de um planejamento ou não para a realização desse ato, em todos os casos apresentados ficou evidente a intenção de envolver o outro na cena traumática, chamando para elas o olhar e atenção dos mesmos.

Os resultados permitiram entender que algumas dessas mulheres não tinham a intenção declarada de encontrar a morte a partir desse ato; aliás, muitas sequer conheciam a gravidade do trauma de uma queimadura. A agressão, que ficou exposta em seus corpos, fala na verdade de uma agressão interpessoal que as mesmas vinham experienciando, mas que não conseguiram expressar ou resolver de outra forma, por isso, o conflito acabou sendo expresso em seus próprios corpos, marcados em sua pele, tendo este ato aparecido em alguns casos como uma forma de cessar a dor vivenciada pelas mesmas.

Os resultados encontrados neste estudo não são passíveis de generalizações, já que foram baseados em uma análise qualitativa, portanto, necessitam ser avaliados com cuidado e reexaminados em pesquisas futuras sobre a temática. Sugere-se que os estudos que vierem a ser realizados sobre este tema possam investigar também os sentimentos e as experiências vivenciadas pelos parceiros(as) das(os) participantes. Além disso, o fato de ter sido realizada somente uma entrevista, pode ter limitado a expressão mais profunda sobre os sentimentos relacionados ao ato de queimarem seus corpos. Acredita-se que a proposta de mais entrevistas com as participantes aumentaria o vínculo e poderia também aumen- tar a confiança e a livre expressão das mesmas.

Apesar das limitações, acredita-se que este estudo tenha contribuído para conhecer melhor a experiência vivenciada por pessoas que colocam seus corpos em chamas. Além disso, é importante o investimento em atividades de prevenção e de intervenção visando a promoção da qualidade de vida dessas pessoas que conviverão com as marcas desse acontecimento para o resto de suas vidas. Isso influenciará positivamente na reinserção social e no bem-estar desses sujeitos na relação com si mesmos e com os mais próximos.

\section{Referências}

Ahmadi, A. (2007). Suicide by self-immolation: Comprehensive overview, experiences, and suggestions. Journal of Burn Care \& Research, 28(1), 30-41.

Ahmadi, A., Mohammadi, R., Schwebel, D. C., Yeganeh, N., Sourosh, A., \& Hejazi, S. B. (2009). Familial risk factors for self-immolation: A Case-Control Study. Journal of Women's Health, 18(7), 1025-1031.

Ahmadi, A., Mohammadi, R., Stavrinos, D., Almasi, A., \& Schwebel, D. C. (2008). Self immolation in Iran. Journal of Burn Care \& Rehabilitation, 29(3), 451-460.

Ahmadi, A., \& Ytterstad, B. (2007). Prevention of self-immolation by community-based intervention. Burns, 33(8), 1032-1040.

Alaghehbandan, R., Lari, A. R., Joghataei, M. T., Islami, A., \& Motavalian, A. (2011). A prospective population-based study of suicidal behavior by burns in the province of Ilam, Iran. Burns, 37(1), 164-169.

Chan, R. C., \& Burd, A. (2012) Suicidal burn in Hong Kong. Burns, 38(6), 937-941.

Daigeler, A., Langer, S., Hüllmann, K., Illes, F., Juckel, G., Echterhoff, S., ...Lehnhardt, M. (2009). A Follow-Up Study of Adults With Suicidal Burns: Psychosocial adjustment and quality of life. Journal of Burn Care \& Research, 30(5), 844-851.

Ferreira, L. A., \& Luis, M. A. V. (2002). A construção do processo que culminou num episódio de queimadura: Relato da história de vida de pacientes queimadas. Revista Escola de Enfermaria, 36(2), 125-132. 
Flick, U. (2004). Uma introdução à pesquisa qualitativa (S. Netz, Trad.). Porto Alegre, RS: Bookman. (Original publicado em 2002)

Forster, N. A., Nuñez, D. G., Zingg, M., Haile, S. R., Künzi, W., Giovanoli, P., \& Guggenheim, M. (2012). Attempted suicide by self-immolation is a powerful predictive variable for survival of burn injuries. Journal of Burn Care \& Research, $33(5), 642-648$

Gaspari, V. P. P., \& Botega N. J. (2002). Social support and suicide attempt. Jornal Brasileiro de Psiquiatria, 51(4), 233-240.

Gibbs, G. (2009). Análise de dados qualitativos. Porto Alegre, RS: Artmed.

Gil, A. C. (2010). Como elaborar um projeto de pesquisa (5. ed.). São Paulo, SP: Atlas.

Hanna, V. N., \& Ahmad, A. (2009). Suicide in the Kurdistan Region of Iraq, state of the art. Nordic Journal of Psychiatric, 63(4), 280-284.

Mabrouk, A. R., Omar, A. N. M., Massoud, K., Sherif, M. M., \& Sayed, N. E. (1999). Suicide by burns: A tragic end. Burns, 25(4), 337-339.

Macedo, J. L. S., Rosa, S. C., \& Silva, M. G. (2011). Queimaduras autoinfligidas: Tentativa de suicídio. Revista do Colégio Brasileiro de Cirurgiões, 38(6), 387-391.

Macedo, M. M. K., \& Werlang, B. S. G. (2007). Trauma, dor e ato: $\mathrm{O}$ olhar da psicanálise sobre uma tentativa de suicídio. Ágora, 10(1), 86-106.

Macente, L. B., Santos, E. G., \& Zandonade, E. (2009). Tentativas de suicídio e suicídio em município de cultura pomerana no interior do estado do Espírito Santo. Jornal Brasileiro de Psiquiatria, 58(4), 238-244.

Makhlouf, F., Alvarez, J. C., \& de la Grandmaison, G. L. (2011). Suicidal and criminal immolations: An 18-year study and review of the literature. Legal Medicine, 13(2), 98-102.

O’Donoghue, J. M., Panchal, J. L., O'Sullivan, S. T., O' Shaughnessy, M., O'Connor, T. P. F., Keeley, H., \& Kelleher, M. J. (1998). A study of suicide and attempted suicide by self-immolation in Irish psychiatric population: An increasing problem. Burns, 24(2), 144-146.

Prieto, D., \& Tavares, M. (2005). Fatores de risco para suicídio e tentativa de suicídio: Incidência, eventos estressores e transtornos mentais. Jornal Brasileiro de Psiquiatria, 54(2), 146-154.
Rezaie, L., Khazaie, H., Soleimani, A., \& Schwebel, D. C. (2011). Self-immolation a predictable method of suicide: A comparison study of warning signs for suicide by self-immolation and by self-poisoning. Burns, 37(8), 1419-1426.

Rothschild, M. A., Raatschen, H. J., \& Schneider. V. (2001). Suicide by self-immolation in Berlin from 1990 to 2000. Forensic Science International, 124(2-3), 163-166.

Santos, S. A., Lovisi, G., Legay, L., \& Abelha, L. (2009). Prevalência de transtornos mentais nas tentativas de suicídio em um hospital de emergência no Rio de Janeiro, Brasil. Caderno de Saúde Pública, 25(9), 2064-2074.

Taghaddosinejad, F., Sheikhazadi, A., Behnoush, B., Reshadati, J., \& Anary, S. H. S. (2010). A Survey of Suicide by Burning in Tehran, Iran. Acta Medica Iranica, 48(4), 266-272.

Werlang, B. S. G. (2012). Autópsia Psicológica, importante estratégia de avaliação retrospectiva. Ciência \& Saúde Coletiva, 17(8), 1955-1962.

Werlang, B. S. G., \& Botega, N. J. (2004). Comportamento suicida. Porto Alegre, RS: Artmed.

Recebido: $14 / 05 / 2012$

$1^{a}$ revisão: $24 / 09 / 2013$ Aceite final: 07/10/2013 